\title{
STUDI TINGKAT KEPUASAN STAKEHOLDERS TERHADAP KOMPETENSI LULUSAN PRODI PENDIDIKAN AGAMA ISLAM FAKULTAS TARBIYAH DAN KEGURUAN UIN RADEN INTAN LAMPUNG DI KOTA BANDAR LAMPUNG
}

\author{
${ }^{1}$ Saiful Bahri, ${ }^{2}$ Heru Juabdin Sada, \\ ${ }^{1,2}$ Universitas Islam Negeri Raden Intan Lampung, Indonesia \\ 1 saifulbahri@ radenintan.ac.id, ${ }^{2}$ herujuabdin@ radenintan.ac.id
}

\begin{abstract}
The purpose of this paper is to determine the level of stakeholder satisfaction with pedagogical competencies, personality competencies, social competencies and professional competencies of alumni of PAI FTK UIN Raden Intan Lampung in high school in Bandar Lampung. The study was conducted using a survey method that is quantitative research conducted by giving the same questions to the respondents and then all answers were recorded, processed and analyzed. The population and sample in this study were all PAI alumni and school principals/waka who was in three schools representing the accreditation of $A, B$, and $C$ at the high school level. The method of data collection uses a questionnaire. Data analysis using percentage descriptive analysis. The percentage of descriptive analysis results showed that the level of stakeholder satisfaction with pedagogic competence of Islamic Education Study Program alumni was $77.38 \%$, personality competency $79.76 \%$, social competence $79.17 \%$, the three competencies included in the Very High category, while professional competencies as high as $75 \%$ / medium. This shows that the average alumni competency of PAI study programs at educational institutions is still very high. The conclusion is that the highest competency value is in personality competencies with very high categories. While the lowest is in professional competence with high/medium category values. This result gave birth to the suggestion that for the department of PAI FTK UIN Raden Intan Lampung study program it was hoped that it could improve their competencies, especially on professional competence, so as to provide a maximum level of satisfaction for stakeholders.
\end{abstract}

Keywords: Stakeholders, Competencies, Graduates, PAI Teachers

\begin{abstract}
ABSTRAK
Tujuannya penulisan ini untuk mengetahui tingkat kepuasan stakeholder terhadap kompetensi pedagogik, kompetensi kepribadian, kompetensi sosial dan kompetensi profesional alumni prodi PAI FTK UIN Raden Intan Lampung di sekolah SLTA di Bandar Lampung. Penelitian dilakukan dengan menggunakan metode survey yaitu penelitian kuantitatif yang dilakukan dengan memberikan beberapa pertanyaan yang sama kepada responden untuk kemudian seluruh jawaban dicatat, diolah dan dianalisis. Populasi dan sampel dalam penelitian ini adalah seluruh alumni prodi PAI dan kepala sekolah/waka yang berada di tiga sekolah mewakili predikat Akreditasi A, B dan C di tingkat SLTA. Metode pengumpulan data menggunakan angket. Analisis data menggunakan analisis deskriptif presentase. Hasil analisis deskriptif presentase menunjukkan bahwa tingkat kepuasan stake holder terhadap kompetensi pedagogik alumni prodi PAI sebesar $77.38 \%$, kompetensi kepribadian $79.76 \%$, kompetensi sosial sebesar $79.17 \%$, ketiga kompetensi tersebut termasuk dalam ketegori Sangat Tinggi, sedangkan kompetensi profesional sebesar $75 \%$ termasuk dalam kategori Tinggi/sedang. Hal ini menunjukkan bahwa rata-rata kompetensi alumni prodi PAI di lembaga pendidikan masih tergolong sangat tinggi. Kesimpulannya adalah bahwa nilai kompetensi tertinggi adalah pada kompetensi kepribadian dengan kategori sangat tinggi. Sedang terendah terdapat pada kompetensi profesional dengan nilai kategori tinggi/sedang. Hasil ini melahirkan saran bahwa untuk jurusan prodi PAI FTK UIN Raden Intan Lampung diharapkan dapat meningkatkan kompetensi yang dimiliki, khususnya pada kompetensi profesional, sehingga dapat memberikan tingkat kepuasan yang maksimal bagi stakeholder.
\end{abstract}

Kata Kunci : Stakeholder, Kompetensi, Lulusan, Guru PAI 


\section{PENDAHULUAN}

Perguruan Tinggi merupakan bagian dari lembaga pendidikan yang bertanggung jawab dalam mencerdaskan kehidupan bangsa dan negara Indonesia. Perguruan tinggi sebagai lembaga yang memiliki peran strategis dalam mendorong kemampuan anak bangsa memasuki dunia global, harus konsen mencetak mahasiswa atau mem-produk alumninya untuk menjadi SDM Unggul, sarjana yang memiliki kesiapan dalam memasuki dunia kerja serta mampu mengembangkan kompetensi dan keilmuan yang dimilikinya sesuai dengan tuntutan masyarakat (stakeholder) dan perkembangan Iptek, selain itu perguruan tinggi juga dituntut mampu menghasilkan lulusan yang memiliki daya saing dan siap berkiprah dalam pembangunan (Sari Narulita,2014).

Perguruan Tinggi memiliki kontribusi yang cukup besar dalam meningkatkan kualitas sumber daya manusia (SDM) di sebuah negara (Soni Akhmad Nulhaqim,2015) Peran perguruan tinggi menjadi mutlak dalam mencetak dan menghasilkan sarjana atau alumni yang ahli dalam berbagai bidang keilmuan. Kampus harus benar-benar dapat menjadi rumah tumbuh kembang intelektual bagi para pembelajar, menjadi pusat pencerahan dan transformasi knowledge (pengetahuan) eksperiance (pengalaman), value (nilai) dan sosio culture (budaya sosial) akademik sesuai dengan bidang keilmuan yang digelutinya. Secara alamiah ada hubungan timbal balik dalam konsep memberi dan menerima antara masyarakat dan perguruan tinggi, hal ini sesuai dengan pendapat Gafur yang mengatakan bahwa masyarakatlah yang memberikan asupan sumber daya dan dana yang diperlukan universitas (perguruan tinggi), dan masyarakat pula yang nantinya akan menerima atau memanfaatkan hasil pelayanan yang diberikan oleh perguruan tinggi (Gafur,A.H, 2008).

Sejalan dengan itu, Prodi Pendidikan Agama Islam (PAI) Fakultas Tarbiyah dan Keguruan UIN Raden Intan Lampung, dengan predikat akreditasi A saat ini berkomitmen teguh dalam melahirkan para sarjana Pendidkan Agama Islam, yang diproyeksikan pada semua satuan pendidikan disekolah setingkat SLTP dan SLTA. Disamping melahirkan praktisi-praktisi bidang kependidikan Islam yang dibutuhkan masyarakat diwilayah provinsi Lampung dan sekitarnya.

Adapun lulusan yang diharapkan dari prodi PAI terhadap mahasiswanya adalah menjadi Serjana Pendidikan Islam yang profesional, berakhlak mulia dan mampu menjadi teladan yang baik di tengah masyarakat. Serjana Pendidikan Islam yang profesional yang dimaksud adalah serjana pendidikan yang memiliki kompetensi utama sebagaimana yang 
dipersyaratkan oleh Undang-Undang Pendidikan Nasional atau Undang-Undang guru dan dosen, yaitu kompetensi pedagogik, kompetensi kepribadian, kompetensi sosial dan kompetensi profesional (Margaretha Purwanti dan Yovi Anggi Lestari,2018), Disamping itu alumni prodi PAI juga diharapkan bisa memberikan manfaat untuk umat, serta turut mengambil bagian dalam mewujudkan masyarakat madani dan religius.

Saat ini telah banyak lulusan dari prodi PAI ini yang bekerja di berbagai instansi atau lembaga pendidikan (lembaga stakeholder atau user) baik instansi negeri maupun swasta, yang tersebar di berbagai daerah Lampung maupun luar Lampung, guna mendedikasikan ke-ilmuan yang didapat selama dikampus. Sebagian besar Lulusan Prodi ini bergerak dan berkecimpung didunia pendidikan (sekolah ataupun madrasah), dan hanya sebagian kecil saja yang masuk dan berkarir di dunia kerja (non-pendidikan) lainnya. Meski demikian para alumni ini terpantau dan terkoordinasi secara kelembagaan oleh Prodi PAI melalui Ika Alumni untuk melihat tingkat keterserapan, peran dan kontribusinya di lembaga atau stakeholder yang menjadi tempatnya bekerja.

Pembahasan tentang tingkat keterserapan, peran dan kontribusi alumni prodi PAI di instansi stakeholder atau user yang menjadi tempatnya mengabdi ini, menjadi data dan informasi penting guna menakar standar mutu lembaga khususnya Prodi, sekaligus feed back yang berguna dalam mengevaluasi proses pendidikan dan pembelajaran secara umum yang berlangsung di prodi PAI, sehingga membantu prodi, fakultas atau institusi UIN dalam menyusun dan mengembangkan program pendidikan yang memberikan penguatan pada kompetensi atau life skill mahasiswa sesuai dengan kebutuhan dan tuntutan masyarakat/stakeholder.

Dalam konteks ini, mempersiapkan mahasiswa prodi PAI menjadi lulusan atau serjana pendidikan yang memiliki berbagai kompetensi atau life skill yang handal dan siap memasuki dunia kerja adalah sebuah tujuan besar dan menjadi harapan bersama, bukan saja UIN atau Fakultas Tarbiyah secara kelembagaan tetapi juga stakeholder dan masyarakat yang menjadi user dan membutuhkan kehadiran alumni. Harapan masyarakat stakeholder terhadap alumni hanya bisa dipenuhi jika prodi PAI sebagai produser mampu bersinergi dalam menghadirkan alumni yang kompeten, yang bisa memberikan kepuasan secara akademik, sosial dan spiritual, sejalan dengan tuntutan kemajuan ilmu pengetahuan dan teknologi yang begitu cepat dan masif, yang setiap gerak eskalasinya melahirkan problem moral-sosial-akademik lainnya. 
Tingkat kepuasan masyarakat stakeholder sebagai user terhadap alumni prodi PAI ini, bisa ditelusuri pada empat kompetensi utama sebagaimana yang ditetapkan UndangUndang Pendidikan Nasional tahun 2003 tentang kompetensi guru, yaitu kompetensi pedagogik, profesional, sosial dan personal (UU Nomor 14 Tahun, 2005). Ke-empat kompetensi ini merupakan standar mutu pendidik profesional bagi para guru di sekolah atau madrasah. Masing-masing kompetensi ini dengan segala indikatornya menjadi alat ukur dalam menilai kinerja dan profile guru profesional, sekaligus dalam menakar tingkat kepuasan stakeholder atau user.

Inilah yang menjadi latar mengapa tulisan ini menjadi penting, mencoba melihat tingkat kepuasan stakeholder dalam hal ini sekolah (negeri dan swasta) terhadap kompetensi Lulusan prodi atau jurusan Pendidikan Aagama Islam FTK Universitas Islam Negeri Raden Intan Lampung baik pada aspek kompetensi pedagogik, kepribadian, sosial maupun propesional. Dengan kata lain tulisan ini bermaksud memotret dan membahas tingkat kepuasan sekolah atau lembaga pendidikan yang menjadi stakeholders atau user alumni prodi PAI.

Kepuasan memiliki makna yang beragam, kepuasan tidak selamanya diukur dengan uang atau materi, tidak juga itu dilihat dari keterpenuhinya hasrat-hasrat biologis tetapi lebih didasarkan pada pemenuhan rasa atau perasaan tentang apa yang dibutuhkan atau di inginkan setara atau melebihi harapan yang telah ditentukan seseorang. Kepuasan (Satisfaction) berasal dari bahasa latin yaitu satis yang berarti enough atau cukup dan facio yang berarti to do atau melakukan, sehingga kepuasan dapat diartikan sebagai upaya pemenuhan sesuatu atau membuat sesuatu memadai. Sebuah kepuasan juga bisa didefinisikan sebagai persepsi terhadap sesuatu yang telah memenuhi harapannya. Oleh karena itu, seseorang tidak akan puas apabila mempunyai persepsi bahwa harapannya belum terpenuhi. Seseorang akan merasa puas jika persepsinya sama atau lebih besar dari yang diharapkan (Irawan, Handi, 2008).

Kepuasan adalah perasaan senang atau kecewa seseorang yang muncul setelah membandingkan antara persepsi atau kesannya terhadap kinerja (atau hasil) suatu produk dan harapan-harapannya. Kepuasan merupakan fungsi dari persepsi atau kesan atas kinerja dan harapan. Jika kinerja berada dibawah harapan maka pelanggan tidak puas tetapi jika kinerja memenuhi harapan maka pelanggan merasa puas. Jika kinerja melebihi harapan, 
pelanggan amat puas atau senang. Kepuasan yang tinggi melahirkan kelekatan emosional terhadap produk yang diharapkan, bukan hanya kelekatan atau preferensi rasional semata tetapi dapat mendorong kesetiaan pelanggan yang tinggi (Kotler, 2002). Dengan demikian kepuasan memiliki makna suatu perasaan yang dihasilkan dari suatu upaya untuk memenuhi sesuatu atau membuat sesuatu menajadi memadai dan mencukupi sesuai dengan yang diharapkan.

Sedangkan pengertian stakeholder banyak dikemukakan para ahli, diantaranya dikemukakan Ramizes dalam bukunya Cultivating Peace, yang mengidentifikasi berbagai pendapat mengenai stakeholder. Friedman mendefinisikan stakeholder sebagai: "any group or individual who can affector is affected by the achievment of the organization's objectives."(R.E. Freeman, 1984), Riset secara singkat mendefinisikan stakeholders adalah orang dengan suatu kepentingan atau perhatian pada permasalahan tertentu. Sedangkan Grimble and Wellard memandang stakeholders dari segi posisi penting dan pengaruh yang mereka miliki. (Busyra Azheri, 2012) Dari definisi tersebut, maka stakeholders merupakan keterkaitan dan keterikatan seseorang atau lembaga yang dilandasi oleh kepentingan tertentu. Dalam penelitian Yosevita Stakeholders dibagi menjadi 3 kelompok ( Latupapua dan Yosevita, 2015) antara lain:

Stakeholder primer merupakan stakeholder yang terkena dampak secara langsung baik dampak positif maupun dampak negatif dari suatu rencana serta mempunyai kaitan kepentingan langsung dengan kegiatan tersebut. Stakeholders yang memiliki pengaruh dan kepentingan dikatakan sebagai stakeholder primer dan harus dilibatkan penuh dalam tahapan - tahapan kegiatan.

Stakeholder kunci adalah mereka yang memiliki kewenangan legal dalam hal pengambilan keputusan. Di dalam penelitian ini stakeholders kunci adalah stakeholders yang bertanggung jawab dalam pelaksanaan manajemen dan operasional lembaga pendidikan atau sekolah di Bandar Lampung.

Stakeholders pendukung merupakan stakeholder yang tidak memiliki kepentingan langsung terhadap suatu rencana tetapi memiliki kepedulian yang besar terhadap proses pengembangan. Stakeholders pendukung menjadi fasilitator dalam proses pengembangan suatu kegiatan dan berpengaruh terhadap pengambilan keputusan. Stakeholders pendukung meliputi para investor atau pihak swasta, LSM, dan peneliti. 
Sedangkan indikator kepuasan Menurut teori Kottler, menyatakan kunci untuk mempertahankan pelanggan adalah kepuasan konsumen. Indikator Kepuasan konsumen dapat dilihat dari :

Re-purchase : membeli kembali, dimana pelanggan tersebut akan kembali kepada perusahaan untuk mencari barang / jasa. Menciptakan Word-of-Mouth : Dalam hal ini, pelanggan akan mengatakan hal-hal yang baik tentang perusahaan kepada orang lain

Menciptakan Citra Merek : Pelanggan akan kurang memperhatikan merek dan iklan dari produk pesaing, Menciptakan keputusan Pembelian pada Perusahaan yang sama : Membeli produk lain dari perusahaan yang sama (Kotler, 2002).

Dalam konteks Pendidikan, stakeholder adalah masyarakat peduli sekolah yang merupakan warga atau individu yang berada di sekolah dan di sekitar sekolah yang berhubungan secara langsung maupun tidak langsung terhadap manajemen sekolah, memiliki kesadaran social dan mempunyai pengaruh terhadap sekolah. Stakeholder adalah segenap komponen terkait yang memiliki hak serta kewajiban yang sama dalam merencanakan, melaksanakan dan melakukan pengawasan terhadap program pendidikan Secara umum istilah stakeholder diartikan sebagai pemangku kepentingan, dan secara sederhana, stakeholder sering dinyatakan sebagai para pihak, lintas pelaku, atau pihakpihak yang terkait dengan suatu isu atau suatu rencana. Pasal 56 Undang-Undang Sistem Pendidikan Nasional tentang menjelaskan bahwa mengenai stakeholder, yaitu:

Pertama: Masyarakat berperan dalam peningkatan mutu pelayanan pendidikan yang meliputi perencanaan, pengawasan dan evaluasi program pendidikan melalui dewan pendidikan dan komite sekolah (Slameto, 2010)

Kedua: Dewan pendidikan sebagai lembaga mandiri dibentuk dan berperan dalam peningkatan mutu pelayanan pendidikan tenaga, sarana dan prasarana, serta pengawasan pendidikan pada tingkat nasional, provinsi, dan kabupaten/kota yang tidak mempunyai hubungan hirarkis.

Komite Sekolah merupakan sebuah badan mandiri yang mewadahi peran serta masyarakat dalam rangka meningkatkan mutu, pemerataan dan efisiensi pengelolaan pendidikan di satuan pendidikan baik pada pendidikan prasekolah, jalur pendidikan sekolah, maupun jalur pendidikan luar sekolah (Yunita Endra Megiati, 2016). Komite 
sekolah sebagai lembaga mandiri, dibentuk dan berperan dalam peningkatan mutu pelayanan dengan memberikan pertimbangan, arahan dan dukungan tenaga, sarana dan prasarana, serta pengawasan pendidikan pada tingkatan satuan pendidikan (Kompri, 2014) Sedangkan kepuasan Nasution (Nasution,2004) mengutip Tse dan Wilton menyatakan bahwa kepuasan atau ketidakpuasan pelanggan adalah respons pelanggan terhadap evaluasi ketidaksesuaian/diskormasi yang dirasakan antara harapan sebelumnya (atau norma kinerja lainnya) dan kinerja aktual produk yang dirasakan setelah pemakaiannya. Apabila dikaitkan dengan lembaga pendidikan, maka sesuatu yang didapatkan atau dirasakan oleh masyarakat pengguna lembaga pendidikan, sesuai dengan apa yang ia harapkan dari lembaga pendidikan tersebut. Kurikulum yang berorientasi pada pencapaian kompetensi, kompetensi diklasifikasikan dalam 3 bentuk yang salah satunya adalah kompetensi lulusan. Kompetensi lulusan, yaitu kemampuan minimal yang harus dicapai oleh peserta didik setelah tamat mengikuti pendidikan pada jenjang atau satuan pendidikan tertentu. Kompetensi berasal dari bahasa Inggris, competence yang berarti kecakapan dan kemampuan (Musfah dan Jejen, 2015). Kompetensi merupakan gabungan antar pengetahuan, sikap, dan keterampilan yang dimiliki oleh guru untuk mencapai tujuan pembelajaran.

Dalam UU guru dan dosen, Bab I ( Ketentuan Umum ) pasal 1 ayat 10 , bahwa pengertian kompetensi adalah " seperangkat pengetahuan, keterampilan, dan perilaku yang harus dimiliki, dihayati, dan dikuasai oleh guru atau dosen dalam melaksanakan tugas keprofesionalan (UU Nomor 14 Tahun, 2015).

Kompetensi lulusan yang dimaksud disini adalah seperangkat kemampuan yang harus dimiliki oleh lulusan (Guru atau calon guru) meliputi pengetahuan, sikap dan keterampilan kerja yang terstandar, yang didapat melalui pendidikan dan pelatihan khusus dan tertentu sehingga menjadi karakter pribadi yang bermutu dan professional (E. Mulyasa, 2006)

Kompetensi guru sebagaimana dimaksud dalam Undang-Undang No. 20 Tahun 2003 tentang Guru dan Dosen dan Peraturan Pemerintah No. 19 tahun 2005 tentang Satandar Nasional Pendidikan, pada Pasal 8 meliputi: kompetensi pedagogik, kompetensi kepribadian, kompetensi sosial, dan kompetensi professional (Muh. Hambali, 2016) ${ }^{\circ} \mathrm{Ke}-$ empat kompetensi ini diperoleh melalui pendidikan profesi. 1. Kompetensi Pedagogik, kompetensi pedagogik adalah seperangkat kemampuan dalam mengelola pembelajaran peserta didik disekolah. 2. Kompetensi Kepribadian, kompetensi kepribadian adalah 
kemampuan kepribadian yang mantap, berakhlak mulia, arif dan berwibawa serta menjadi teladan peserta didik. 3. Kompetensi Sosial, kompetensi sosial adalah Kemampuan guru untuk berkomunikasi dan berinteraksi secara efektif dan efisien dengan peserta didik, sesama guru, orangtua/wali, dan masyarakat sekitar. 4. Kompetensi Profesional, kompetensi profesional adalah Kemampuan penguasaan materi pelajaran secara luas dan mendalam.(Musfah dan Jejen, 2015)

Adapun keempat standar kompetensi tersebut wajib dimiliki oleh seorang guru. Berikut penjelasan dan indikator keempat kompetensi tersebut:

Kompetensi Pedagogik menurut Sardiman A. M., merupakan kemampuan pemahaman terhadap peserta didik, perencanaan dan pelaksanaan pembelajaran, evaluasi hasil belajar, dan pengembangan peserta didik untuk mengaktualisasikan berbagai potensi yang dimilikinya. (Sardiman A.M, 2004). Adapun kompetensi pedagogik meliputi : Mengenal anak didiknya, menguasai teori-teori tentang pendidikan, bahan pelajaran, macam-macam teknik dan metode pembelajaran, menyusun rencana pelaksanaan pembelajaran (RPP) serta mengevaluasi proses dan hasil pembelajaran.

Kompetensi Kepribadian ialah kemampuan individu atau personal yang mencerminkan kepribadian yang stabil, bijaksana, dewasa, berwibawa, dan dapat menjadi teladan bagi peserta didiknya serta memiliki akhlak yang mulia. (Sjarkawi, 2006) Kompetensi kepribadian ini berkemampuan dalam mengaktualisasikan diri sebagai pendidik yang disiplin, jujur, berwawasan luas, bertanggung jawab dan dapat menjadi sumber inspirasi posirif bagi para peserta didiknya.

Kompetensi Sosial ialah kemampuan guru dalam melakukan komunikasi baik lisan, tulisan maupun perbuatan kepada peserta didik, tenaga-tenaga kependidikan, wali murid, maupun masyarakat sekitar dengan cara yang efektif, ramah atau santun dan sesuai dengan adat dan norma yang berlaku. Selain itu, dalam kompetensi sosial ini, guru mampu bekerjasama dan beradaptasi dengan keanekaragaman suku dan budaya di tempat melaksanakannya tugas.

Kompetensi Profesional merupakan kemampuan dalam penguasaan materi pembalajaran secara mendalam dan luas (Nasir Usma, 2017), tidak hanya penguasaan materi pelajaran saja, namun juga penguasaan terhadap materi-materi 
kurikulum yang berlaku, konsep dan struktur keilmuan, masalah-masalah pendidikan dan wawasan yang memadai terhadap materi-materi yang bersangkutan.

\section{METODE PENELITIAN}

Teknik pengumpulan data dilakukan melalui kegiatan penelitian kepustakaan (library research) dari berbagai komponen sekolah yang dijadikan sumber data seperti. Sedangkan metode pengumpulan data yang dilakukan dalam penelitian ini adalah sebagai berikut:

Studi Literatur: Metode ini merupakan tahap awal kegiatan pengkajian. Dari kegiatan ini diharapkan akan tercipta peta (mapping) awal serta rancangan alternatif model yang akan digunakan dalam penelitian. Model (skema) kegiatan pembinaan siswa juga akan dibentuk dari hasil kajian literatur, yang dikombinasikan dengan hasil survey. Dari hasil studi literatur ini juga diharapkan menjadi salah satu masukan untuk menyusun daftar pertanyaan terstruktur (kuesioner), untuk siswa berprestasi dan Guru Pembina yang akan dijadikan responden. Survey (Wawancara): Metode atau teknik ini dilakukan untuk menghimpun data primer berupa informasi langsung yang akan diperoleh dari responden yang akan ditentukan, kemudian. Metode ini dilengkapi dengan seperangkat kuesioner yang berisikan sejumlah pertanyaan terstruktur.(Sugiyono, 2003) Dari jawaban atas pertanyaan kuesioner, diharapkan dapat dijadikan bahan olahan untuk teknik analisis kuantitatif dan kualitatif yang digunakan.

teknik pengambilan sampel yang digunakan adalah teknik "Multistage Random Sampling", yakni siswa berprestasi pada MAN I Model Kota Bandar Lampung, dengan tahapan sebagai berikut: Tahap pertama, untuk menentukan sampel Siswa, digunakan teknik purposif, yaitu dipilih dengan disengaja siswa yang berprestasi di MAN I Model Kota Bandar Lampung. Pada tahap pertama ditentukan siswa yang akan menjadi sampel adalah siswa yang berprestasi, sedangkan untuk sampel organisasi Kesiswaan adalah: Kepramukaan dan Palang Merah Remaja; Tahap kedua, untuk menentukan jumlah sampel pada masing-masing kelompok, digunakan metode Simple Random Sampling, dengan sampling frame adalah siswa berprestasi di MAN I Model Kota Bandar Lampung. Jumlah sampel disesuaikan dengan besarnya standar deviasi yang diperoleh berdasarkan survei pendahuluan, dan jumlah populasi $(\mathrm{N})$ siswa. Rumus yang digunakan untuk menentukan jumlah sampel total (n) pada metode Simple Random Sampling. Jumlah siswa pada MAN I 
Model Kota Bandar Lampung adalah 1.250 siswa. Tahap Ketiga, persiapan rancangan kuesioner berdasarkan variabel penelitian dan koordinasi pelaksanaan penyebaran kuesioner.

Kerangka Fikir

Kepuasan Stakeholder terhadap Kompetensi Lulusan Prodi PAI

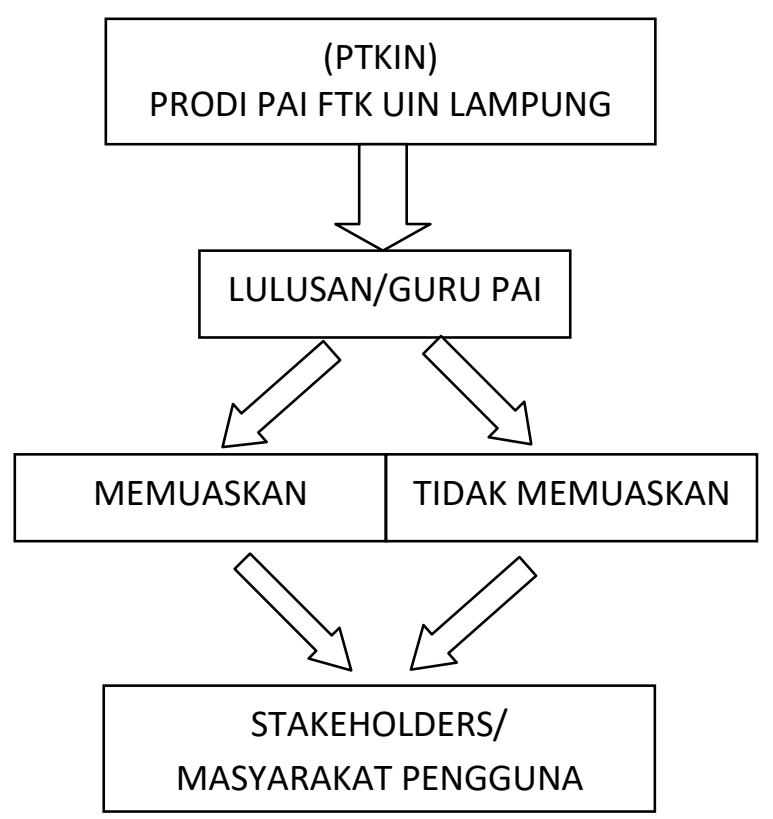

\section{HASIL PENELITIAN DAN PEMBAHASAN}

Data tentang tingkat kepuasan stakeholder terhadap kompetensi lulusan atau alumni prodi PAI disekolah SLTA, khususnya di SMA 9 Bandar Lampung, SMK 7 Bandar Lampung dan SMK Miftahul Ulum Bandar Lampung dapat digambarkan lebih jauh dibawah ini :

1. Kepuasan Stakeholder terhadap Kompetensi Pedagogik Alumni

\begin{tabular}{|c|c|c|c|c|c|c|c|c|c|c|c|}
\hline \multirow{2}{*}{ NO. } & \multirow{2}{*}{ NAMA SEKOLAH } & \multicolumn{7}{|c|}{$\begin{array}{c}\text { INDIKATOR KOMPETENSI } \\
\text { PEDAGOGIK }\end{array}$} & \multirow{2}{*}{ JML } & \multirow{2}{*}{$\%$} & \multirow{2}{*}{ KET. } \\
\hline & & 1 & 2 & 3 & 4 & 5 & 6 & 7 & & & \\
\hline 1 & SMA 9 Bandar Lampung & 4 & 3 & 3 & 4 & 3 & 3 & 3 & 23 & 82.14 & Sangat Baik \\
\hline 2 & SMK 7 Bandar Lampung & 3 & 2 & 4 & 4 & 2 & 3 & 2 & 20 & 71.43 & Baik \\
\hline 3 & SMK Miftahul Ulum BL & 4 & 3 & 3 & 4 & 3 & 3 & 2 & 22 & 78.57 & Sangat Baik \\
\hline & & & & & & & & & ta $\%$ & 77.38 & Sangat Baik \\
\hline
\end{tabular}




\section{Keterangan Indikator Kompetensi Pedagogik :}

1 Pemahaman kondisi phisik/psikologis peserta didik

2 Pemahaman teori belajar dan pembelajaran PAI

3 Pemahaman tentang metode dan strategi pembelajaran serta penerapannya

4 Kemampuan mendesain perencanaan pembelajaran PAI (RPP/silabus, prota/prosem)

5 Kemampuan mendesain pelaksanaan pembelajaran PAI (metode, strategi, media, dll.)

6 Kamampuan dalam merancang dan melaksanakan evaluasi pembelajaran PAI

7 Kemampuan dalam mengembangkan pembelajaran dan kompetensi peserta didik

\section{Kriteria Penilaian}

$22-28$ : Sangat Baik $8-14$ : Cukup

$$
15-21: \text { Baik } \quad 1-7: \text { Kurang Baik }
$$

Dari tabel diatas dapat disampaikan bahwa tingkat kepuasan stakeholder/pennguna terhadap kompetensi pedagogik guru PAI di SMA 9 kota Bandar Lampung masuk katagori "sangat baik" dengan prosentasi kepuasannya mencapai (82 \%), sedangkan di SMK 7 Sukarame masuk katogori "baik" dengan prosentasi (75\%) dan di SMK Miftahul Ulum Bandar Lampung tingkat kepuasan stakeholder-nya masuk katagori "sangat baik" dengan prosentasi $(78.57 \%)$. Ini maknanya bahwa di tiga SLTA di kota Bandar Lampung yang menjadi objek dalam penenlitian ini menunjukan bahwa tingkat kompetensi pedagogik alumni prodi PAI sudah sangat baik, yang juga berarti bahwa tingkat kepuasan stakeholder terhadap kompetensi pedagogik guru PAI sangat tinggi. Ini menandakan bahwa secara umum tingkat kepuasan stakeholder terhadap kompetensi pedagogik alumni prodi atau jurusa khususnya disekolah-sekolah di Bandar Lampung relatif sangat baik dan bisa diterima.

\section{Kepuasan Stakeholder terhadap Kompetensi Kepribadian Alumni}

\begin{tabular}{|c|c|c|c|c|c|c|c|c|c|c|c|}
\hline \multirow[t]{2}{*}{ NO } & \multirow{2}{*}{ NAMA SEKOLAH } & \multicolumn{7}{|c|}{$\begin{array}{c}\text { INDIKATOR KOMPETENSI } \\
\text { KEPRIBADIAN }\end{array}$} & \multirow[t]{2}{*}{ JML } & \multirow[t]{2}{*}{$\%$} & \multirow[t]{2}{*}{ KET. } \\
\hline & & $\mathbf{1}$ & 2 & 3 & 4 & 5 & 6 & 7 & & & \\
\hline 1 & SMA 9 Bandar Lampung & 4 & 3 & 3 & 4 & 3 & 3 & 3 & 23 & 82.14 & Sangat Baik \\
\hline 2 & SMK 7 Bandar Lampung & 3 & 2 & 3 & 2 & 2 & 3 & 4 & 19 & 71.43 & Baik \\
\hline 3 & SMK Miftahul Ulum BL & 3 & 4 & 3 & 3 & 3 & 4 & 4 & 24 & 85.71 & Sangat Baik \\
\hline & \multicolumn{9}{|c|}{ Rata-Rata \% } & 79.76 & Sangat Baik \\
\hline
\end{tabular}

\section{Keterangan Indikator Kompetensi Kepribadian :}

1 Memiliki kepribadian yang mantap dan stabil

2 Memiliki pribadi yang terbuka, arif dan bijaksana

3 Memiliki kedewasaan, mandiri dan berwibawa 
4 desiplin, jujur dan tanggung jawab

5 Memiliki etos kerja dan berwawasan luas

6 Berakhlak mulya

7 Mampu menjadi tauladan dan inspirator (positif) bagi peserta didik

\section{Kriteria Penilaian}

22 - 28 : Sangat Baik

$15-21$ : Baik

$$
\begin{aligned}
& 8-14: \text { Cukuk } \\
& 1-7: \text { Kurang Baik }
\end{aligned}
$$

Pada tabel 2 yang menggambarkan kondisi kompetensi kepribadian guru PAI alumni prodi PAI UIN raden Intan Lampung diatas dapat dijelaskan bahwa tingkat kepuasan lembaga pennguna terhadap kompetensi kepribadian guru PAI di SMA 9 kota Bandar Lampung masuk katagori "sangat baik" dengan prosentasinya kepuasannya (82.14 \%), begitupun di SMK Miftahul Ulum Bandar Lampung tingkat kepuasan stakeholder terhadap kompetensi kepribadian guru PAI masuk katagori "sangat baik" dengan prosentasi (85.71 \%). sedangkan di SMK 7 Sukarame hanya masuk katogori "baik" dengan prosentasi $(71.43 \%)$ dan senada dengan tingkat kepuasan stakeholder terhadap kompetensi pedagogik diatas, tingkat kepuasan stakeholder terhadap kompetensi kepribadian guru PAI juga masuk katagori sangat baik dengan tingkat prosentasi diatas 80 -an \%. Ini juga artinya bahwa di tiga SLTA yang mewakili 3 peringkat akreditasi tingkat SLTA di kota Bandar Lampung tersebut, tingkat kompetensi kepribadian alumni prodi PAI sangat tinggi, dan secara umum tingkat kepuasan stakeholder terhadap kompetensi kepribadian alumni prodi PAI khususnya disekolah-sekolah di Bandar Lampung relatif sangat baik dan juga bisa diterima.

\begin{tabular}{|c|c|c|c|c|c|c|c|c|c|c|}
\hline \multirow{2}{*}{ NO. } & \multirow{2}{*}{ NAMA SEKOLAH } & \multicolumn{6}{|c|}{$\begin{array}{l}\text { INDIKATOR KOMPETENSI } \\
\text { SOSIAL } \\
\end{array}$} & \multirow{2}{*}{ JML } & \multirow[t]{2}{*}{$\%$} & \multirow{2}{*}{ KET. } \\
\hline & & 1 & 2 & 3 & 4 & 5 & 6 & & & \\
\hline 1 & SMA 9 Bandar Lampung & 4 & 4 & 3 & 4 & 4 & 3 & 22 & 91.67 & Sangat Baik \\
\hline 2 & SMK 7 Bandar Lampung & 4 & 3 & 2 & 4 & 3 & 2 & 18 & 75.00 & Baik \\
\hline 3 & SMK Miftahul Ulum BL & 4 & 2 & 2 & 3 & 3 & 3 & 17 & 70.83 & Baik \\
\hline & \multicolumn{8}{|c|}{ Rata-Rata \% } & 79.17 & Sangat Baik \\
\hline
\end{tabular}

\section{Kepuasan Stakeholder terhadap Kompetensi Sosial Alumni}

\section{Keterangan Indikator Kompetensi Sosial :}

1 Keaktifan dalam membangun komunikasi dengan peserta didik

2 Keaktifan dalam membangun komunikasi dengan para guru disekolah maupun diluar

3 Keaktifan dalam membangun komunikasi dengan wali-murid dan atau warga masyarakat sekitar 
4 Memiliki sifat ramah dan santun pada sesame

5 Mampu bekerja sama dengan peserta didik, para guru, wali-murid dan masyarakat

6 Mampu beradaptasi dengan semua suku, bahasa, budaya, dan tradisi keagamaan masyarakat

\section{Kriteria Penilaian}

$19-24$ : Sangat Baik

$13-18$ : Baik

$$
\begin{aligned}
& 7-12: \text { Cukuk } \\
& 1-6: \text { Kurang Baik }
\end{aligned}
$$

Sedikit berbeda dengan 2 tabel sebelumnya, pada tabel 3 yang menggambarkan kondisi kompetensi sosial guru PAI alumni prodi PAI UIN raden Intan Lampung diatas, dapat dipahami bahwa untuk tingkat kepuasan pennguna terhadap kompetensi sosial guru PAI di SMA 9 kota Bandar Lampung masih masuk dalam katagori "sangat baik" dengan prosentasinya kepuasannya (91.67\%), tetapi berbeda di SMK 7 Sukarame dan SMK Miftahul Ulum Bandar Lampung tingkat kepuasan stakeholder terhadap kompetensi sosial guru PAI sedikit menurun hanya dikatagori "baik" saja dengan prosentasi di SMK 7 Sukarame (75.00 \%). sedangkan di SMK Miftahul Ulum Bandar Lampung (70.83 \%). Meski demikian tingkat kepuasan stakeholder terhadap kompetensi sosial guru PAI diatas, masih masuk katagori tinggi dengan tingkat prosentasi diatas 70-an \%. Yang menandakan bahwa di tiga SLTA di kota Bandar Lampung tersebut, tingkat kompetensi sosial alumni prodi PAI secara umum disekolah-sekolah di kota Bandar Lampung masih relatif baik dan juga bisa diterima.

\begin{tabular}{|c|c|c|c|c|c|c|c|c|c|}
\hline \multirow[t]{2}{*}{ NO. } & \multirow[t]{2}{*}{ NAMA SEKOLAH } & \multicolumn{5}{|c|}{$\begin{array}{c}\text { INDIKATOR KOMPETENSI } \\
\text { PROFESIONAL }\end{array}$} & \multirow[t]{2}{*}{ JML } & \multirow[t]{2}{*}{$\%$} & \multirow[t]{2}{*}{ KET. } \\
\hline & & 1 & 2 & 3 & 4 & 5 & & & \\
\hline 1 & SMA 9 Bandar Lampung & 4 & 3 & 3 & 2 & 4 & 16 & 80 & Sangat Baik \\
\hline 2 & SMK 7 Bandar Lampung & 3 & 2 & 3 & 3 & 3 & 14 & 70 & Baik \\
\hline 3 & SMK Miftahul Ulum BL & 3 & 2 & 3 & 3 & 4 & 15 & 75 & Baik \\
\hline & \multicolumn{7}{|c|}{ Rata-Rata \% } & 75 & Baik \\
\hline
\end{tabular}

\section{Kepuasan Stakeholder terhadap Kompetensi Profesional Alumni}

\section{Keterangan Indikator Kompetensi Profesional :}

1 Penguasaan konten keilmuan bidang PAI

2 Pemahaman konsep, struktur dan ruang lingkup keilmuan PAI

3 Pemahaman standar kompetensi dan kompetensi dasar keilmuan yang hendak dicapai

4 Kemampuan dalam mengembangkan dan pendalaman materi ajar

5 Kemampuan melaksanakan dan mempraktekan ibadah dan amaliah keagamaan lainya

\section{Kriteria Penilaian}

$16-20$ : Sangat Baik $\quad 6-10:$ Cukup 
$11-15$ : Baik

$$
1 \text { - } 5 \text { : Kurang Baik }
$$

Pada tabel 4 diatas, tergambar tentang kondisi kompetensi Profesional guru PAI alumni prodi PAI UIN raden Intan Lampung, dimana untuk tingkat kepuasan stakeholder terhadap kompetensi Profesional guru PAI di tiga SLTA tersebut didapat data sebagai berikut : untuk SMA 9 kota Bandar Lampung kompetensi Profesional guru PAI masih dalam katagori "sangat baik" dengan prosentasinya kepuasannya (80\%), tetapi di SMK 7 Sukarame dan SMK Miftahul Ulum Bandar Lampung tingkat kepuasan stakeholder terhadap kompetensi Profesional guru PAI hanya dikatagori "baik" saja dengan prosentasi di SMK 7 Sukarame (70 \%). sedangkan di SMK Miftahul Ulum Bandar Lampung (75 \%). Meski tingkat kepuasan stakeholder terhadap kompetensi Profesional guru PAI dalam katagori baik, tetapi secara umum stakeholder di tiga SLTA di kota Bandar Lampung tersebut, menilai masih tinggi, dan ini menandakan tingkat kepuasan stakeholder terhadap kompetensi Profesional alumni prodi PAI secara umum masih relatif baik dan bisa diterima. Sajian dan pembahasan tabel hasil penelitian (tabel 1-2-3) tentang tingkat kepuasan stakeholder terhadap kompetensi yang dimiliki lulusan alumni Prodi PAI Fakultas Tarbiyah dan Keguruan UIN Raden Intan Lampung, khususnya di SMA 9, SMK 7 dan SMK Miftahul Ulum Bandar Lampung, dapat dijelaskan lebih jauh dibawah ini dimasingmasing sekolah tentang kondisi kompetensi lulusan prodi PAI yang menjadi guru PAI dimasing-masing sekolah tersebut, yaitu sebagai berikut :

Gambar Diagram 1

Hasil Penilaian Kompetensi Guru PAI

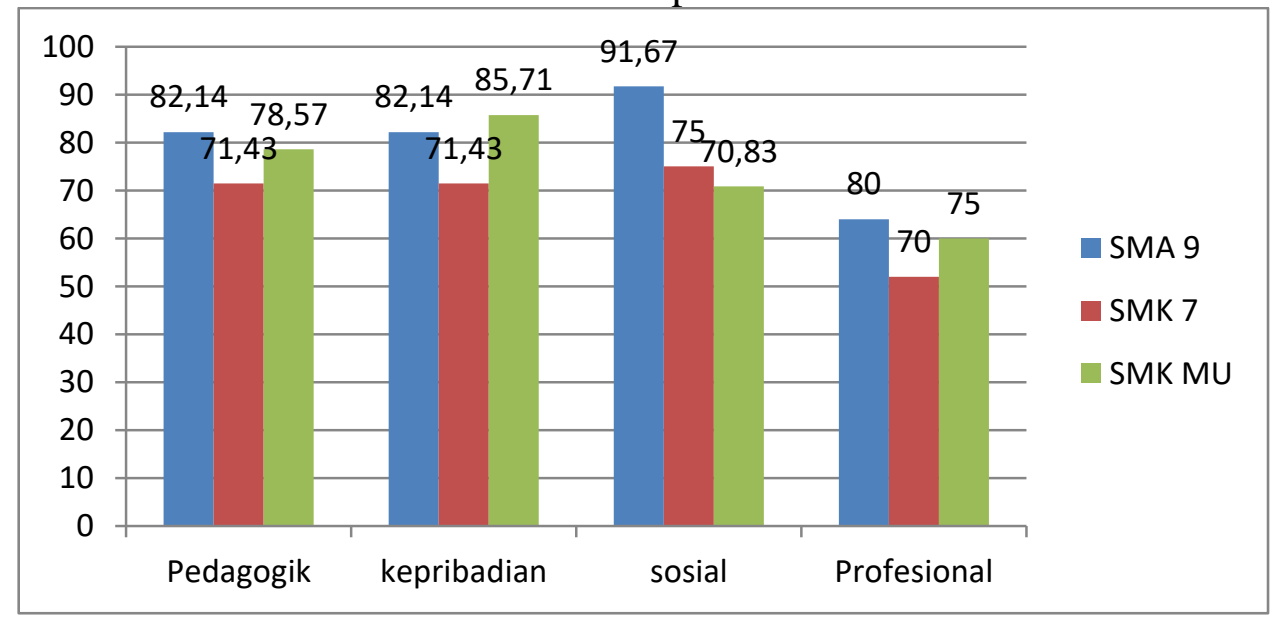

Dari gambar diagram diatas dapat disimpulkan bahwa kompetensi alumni prodi PAI di SMA 9 kota Bandar Lampung, secara faktual telah memberikan kepuasan bagi semua 
civitas sekolah, khususnya dalam pandangan pimpinan SMA 9 kota Bandar Lampung, baik pada aspek kompetensi pedagogik, kepribadian, sosial maupun kompetensi profesional, dan jika dirata-rata maka perolehan tingkat kepuasannya $84 \%$, yang bermakna Sangat Baik atau Sangat Puas. Kinerja guru PAI sangat baik, hal ini dibuktikan dengan pengamalan dan peraktek keagamaan yang ditanamkan setiap hari kepada siswa disekolah ini, seperti sholat jamaah, kajian keagamaan siswa (Rohis), PHBI, BBQ dan pengamalan sosial keagamaan lainnya

Sedangkan kompetensi guru PAI di SMK 7 Bandar Lampung secara umum berada pada penilaian BAIK, dengan kata lain bahwa tingkat kepuasan stakeholder dalam hal ini SMK 7 Bandar Lampung berada pada kondisi baik atau sedang, kompetensi guru alumni prodi PAI disekolah ini belum memberikan tingkat kepuasan yang maksimal, khususnya pada semua aspek kompetensi, hal ini karena tingkat capaian kepuasan stakeholder dalam prosentasi masih berada pada rerata 70 -an \%. Hal ini tentu saja kompetensi guru PAI masih perlu ditingkatkan lagi agar bisa memberikan kepuasan yang maksimal bagi sekolah sebagai stakeholder atau user. Dari data profile kompetensi guru PAI di SMK Miftahul Ulum Bandar Lampung secara umum berada pada penilaian BAIK, dengan tingkat kepuasan $75.03 \%$. Dapat disampaikan bahwa tingkat kepuasan stakeholder di SMK Miftahul Ulum berada pada kondisi baik, tetapi di sekolah ini kompetensi guru alumni prodi PAI belum memberikan tingkat kepuasan yang diharapakan, masih perlu ditingkatkan lagi kompetensinya khususnya pada aspek kompetensi sosial dan kompetensi profesional, agar bisa memberikan kepuasan yang maksimal bagi pihak SMK Miftahul Ulum Bandar Lampung. Dari sajian data dan pembahasan diatas, tingkat kepuasan pengguna atau stakeholder terhadap kompetensi alumni prodi PAI disekolah khususnya di SMA 9, SMK 7 dan SMK Miftahul Ulum Bandar Lampung, secara umum dapat disimpulkan pada posisi Baik bahkan mendekati posisi Sangat Baik, dengan kata lain mendekati peringkat Sangat Memuaskan.

\section{SIMPULAN DAN SARAN}

Berdasarkan hasil penelitian dan pembahasan diatas, tingkat kepuasan penguna terhadap kompetensi alumni prodi PAI disekolah Bandar Lampung khususnya di SMA 9, SMK 7 dan SMK Miftahul Ulum Bandar Lampung dapat disimpulkan "sangat baik" baik pada aspek kompetensi pedagogik, kepribadian, sosial maupun kompetensi professional. 
Data tentang ini ditunjukan dengan nilai rata-rata perolehan tingkat kepuasannya, di SMA N 9 (84 \%) tingkat kepuasannya "sangat baik", SMK N 7 (70 \%) tingkat kepuasannya "baik", dan SMK Miftahul Ulum (75 \%) tingkat kepuasannya "sangat baik". saran dalam penulisan ini agar pergurauan tinggi atau fakultas tarbiyah dan keguruan khususnya Prodi PAI senantiasa meningkatkan pelayanan kepada mahasiswa agar kualitas lulusan lebih banyak lagi bermanfaat buat stakeholders.

\section{DAFTAR PUSTAKA}

A.M, S. (2004). Interaksi dan Motivasi Belajar-Mengajar. Jakarta: Rajawaali Pers.

Busyra Azheri. (2012). Corporate Social Responsibility; Dari Voluntary Menjadi Mandatory. Jakarta: Rajawaali Pers.

E. Mulyasa. (2006). Kurikulum Tingkat Satuan Pendidikan. Bandung: PT. Remaja Rosdakarya.

Fitriani, Cut, AR, Murniati, Dan Usma, N. (2017). Kompetensi Profesional Guru Dalam Pengellaan Pembelajaran Di MTS Muhammadiyah Banda Aceh. Jurnal Magister Administrasi Pendidikan Pascasarjana Universitas Syiah Kuala, 5(2), 89.

Gafur, A. H. (2008). Manajemen Penjaminan Mutu Perguruan Tinggi Di Indonesia. Jakarta: Bumi Aksara.

Hambali, M. (2016). Manajemen Pengemabnagan Kompetensi Guru. Jurnal MPI, 1, 71.

Irawan, H. (2008). Sepuluh Prinsip Kepuasan Pelanggan. Jakarta: Elex Media Komputindo Kelompok Gramedia.

Kompri. (2014). Manajemen Sekolah: Teori dan Praktik. Bandung: Alfabeta.

Kotler. (2002). Manajemen Pemasaran Edisi Miilenium Satu. Jakarta: Prenhallindo.

Lestari, Yovi Anggi, dan Purwanti, M. (2018). Hubungan Kompetensi Pedagogik, Profesional, Sosial, dan Kepribadian Pada Guru Sekolah Nonformal X. Jurnal Kependidikan, 2(1), 199.

Megiati, Y. E. (2016). PemberdayaanKomite Sekolah: Kajian Konsep Dan Implementasinya. Jurnal SAP, 1(2), 125.

Musfah, J. (2015). Peningkatan Kompetensi Guru melalui Pelatihan dan Sumber Belajar Teori dan Praktik. Jakarta: Prenadamedia Group.

Narulita, S. (2014). Analisis Kebutuhan Lulusan Jurusan Ilmu Agama Islam (Studi Kinerja Mahasiswa PKL di Beberapa Lembaga / Perusahaan). Jurnal Studi Al-Qur'an, 10(1), 40 . 
Nasution, M. . (2004). Manajemen Jasa Terpadu. Bogor: PT Ghalia Indonesia.

Nurhaqim, S. A. et. a. (2015). Peranan Perguruan Tinggi Dalam Meningkatkan Kualitas Pendidikan Di Indonesia Untuk Menghadapi ASEAN Community 2015. Social Work Jurnal, 6(2), 197.

R.E. Freeman. (1984). Strategic Management: A Stakeholders Approach. Boston: Fitman.

Sjarkawi. (2006). Pembentukan Kepribadian Melalui Peningkatan Pertimbangan Moral. Jakarta: Depdiknas Dirjen Dikti.

Slameto. (2010). Belajar dan Faktor-Faktor yang Mempengaruhinya. Jakarta: PT. Rineka Cipta.

Sugiyono. (2003). Statistika Untuk Penelitian. Bandung: Alfabeta.

UU Nomor 14 Tahun. (2005). menjelaskan bahwa kompetensi adalah seperangkat pengetahuan, keterampilan dan perilaku yang harus dimiliki, dihayati, dan dikuasai oleh guru dan dosen dalam melakukan tugas profesinya.

Yosevita, L. (2015). Implementasi Peran Stakeholder dalam Pengembangan Ekowisata di Taman Nasional Manusela (TNM) di Kabupaten Maluku Tengah. Jurnal Agroforestri $X,(1)$. 